\title{
Managing Travel Agency Customers in an Electronic Business Environment
}

\author{
PhD candidate Hristina Santana \\ University of Economics - Varna, Varna, Bulgaria \\ hristina_santana@ue-varna.bg
}

\begin{abstract}
The current publication is focused on managing travel agency customers in an expanding electronic business environment, influencing process and models of dealing with customers. As human nature is stated to be a factor to consider when e-technology steps in, the author suggests opportunities to keep the balance by implementing e-business initiatives and avoiding mistakes in managing travel agency clients. The purpose is by revealing some practical approaches to propose working examples in servicing in order to emphasize on the importance of travel agencies' role and significance to their customers; reveal the integrant relation between technology and proper customer management; and the importance for the travel agent professionals to improve styles in doing e-business, respecting the human nature of the traveller.
\end{abstract}

Keywords: e-business, digitalization, travel agency customer

JEL Code: Z320; doi:10.36997/IJUSV-ESS/2019.8.1.54

\section{Introduction}

Technological growth revolutionizes entire states' economies and world-wide businesses. Digitalization and expansion of electronic business technologies is a trend that has greatly influenced the tourism industry and the travel agencies. Digitalization played crucial role in the last decades, paving the way for commercial interactions among private individuals on large scale and establishing re-shaping the market environment. The tourism sector comprises several distinct subsectors: e-business, information retrieval, online purchasing and sales, marketing and e-marketing, website analysis and audit, and e-research methods. The rise of digital consumers, the growth of artificial intelligence (AI) techniques, the heterogeneity of digital platforms are defining a new dimension for the travel agency professionals. Horwarth HTL (2015), the world's largest hospitality consulting brand, points out that technological (r)evolution and digital channels belong to the mega trends in tourism which affect and stimulate mid- and long-term tourism development. The World Economic Forum (WEF) (2017, p. 3) states in its report on digital transformation in the aviation, travel and tourism industry that "there is widespread recognition among industry leaders that the role of digital technology is rapidly shifting, from being a driver of marginal efficiency to an enabler of fundamental innovation and disruption". The recent tendencies such as a growing demand for travel, the rise of the digital consumer, changes to the security landscape, and technological innovations such as the rise of intelligent automation and the dominance of electronic sale-platforms keep very high profile when dealing with travel agency customers.

Gelter (2017) provides a comprehensive and contemporary overview of the relevant academic literature inside and outside of the tourism research community. He clusters the various ongoing trends into categories including e-tourism, Internet, smart technology, cloud computing, Big Data, new digital travellers, gamification and social networks: a bundle of mega trends that heavily impact the e-business environment of the "digital tourism". The emerging blockchain technology, still not quite recognized and applied by the travel agency professionals, is described as "a revolutionary technology that in the future will transform financial transactions, and strongly influence the "tourism industry" (p. 74). The author emphasizes on the statement that "blockchain will create unique opportunities for travel companies to track their customer's preferences, build more personalized and meaningful interactions, and extract more value from loyalty programs" ( $p$. 75). Scholars start to identify the industry as part of a modern e-tourism system, which occurs to be quite dynamic and inevitably interconnected with the progress and development of ICTs (Pan, 2015). As a result a diversified toolbox and services, supporting and supplying, accelerating the 
global interactions among the participating elements of the system come into action (Băbăiţă, Ispas, Ghenescu \& Hălălău, 2010). The continuously technological developments and innovation in the travel and tourism industry reveal the sector is still in a transition period. The entire process marks strong transformation from the stakeholders' side and requires specific managerial skills and instruments to be implied when the respective interactions include managing travel agency customers as well.

The object of the current publication is the e-business environment of the travel agencies, the main subject of the study - managing customers in a way of providing services in a situation of widely spread e-sales. The author's purpose is, by making a short theoretical review and revealing some practical approaches to propose working examples in servicing in order to emphasize on the importance of travel agencies' (considering both: tour operators and travel agents intermediaries as a common term) role and significance to their customers.

\section{Customer management and e-business}

Customer retention and loyalty are important goals for successful companies. Any business organisation aims to create, retain and develop a core customer base. Well-structured customer management enables companies to ensure the services they provide are in line with what customers want in order to satisfy their needs and to identify further opportunities for organizational growth. The customer management process is stated to be able to capture customer feedback, to collect valuable information that can be used or implied by the management. It relates to studying customers' behaviour, demographic characteristics, buying preferences, tastes in fashion trends and nowadays in versitile technologies. Managing properly customers, leads to positive feedback which in turn builds effortless interaction and provision of services, opportunity to offer even greater service and keep customer's attention and loyalty. Customer management can initiate at times even negative feedback, which in turn can lead to constructive correction and change in course of servicing. In summary, successful customer management assists organisations to expect and report higher profit rates, income and revenue growth, lower costs and repeating clients.

As e-business stepped in, the communication channel business organisation - customer shifted to a different dimension. Digitalization became the marginal driver, the key market-enabler (Inkson et al, 2018). The e-business environment represents an enormous field of initiatives, trade and e-commerce the Internet is ready to provide often as a complimentary tool to the traditional business models. The revolutionist e-business approach determines extremely easy and quick global reach of services and information at averagely low costs in maintenance, efficient interactions between customer and provider, on-time payment transactions, faster feedbacks and commentary. What makes it useful to the stakeholders is the fact, that it comprises electronic distribution of tourist information on services and products, exerting considerable influence upon contemporary consumer behaviour and their transition to e-traveller. Following the thread of thoughts, there are publications exploring factors and determinants, identifying consumers' apprehension and behaviour towards e-tourism services (Bajpai, Lee, 2015), as well as their protection while purchasing online travel services and products (Nedelea, Bălan, 2010) in the enormous e-business environment. In the meantime it offered greater Internet visibility to the organisations, enabling the travel agencies as well to create and apply efficient toolbox of travel processes management, smooth and effortless inter-partnering communications and better customeragency interaction.

Therefore, there is the need for a specific innovation and even intervention, when speaking of managing customers in e-business environment - technological and interpersonal one. Recently digitalization and e-business initiatives, such as blockchain technology (BCT) are broadly acknowledged as the driver of a next technological revolution (Calvaresi, et al, 2018). By any means, they create unique opportunities for the tourism sector and the companies engaged in the travel and tourism industry. However, there is the necessity for downsizing the hype and the 
magnifying effect of the mentioned above, because e-business is a supplier of many options to the travel organisation, but is not going to change everything. Tourism business is entirely people orientated and humans as customers and users of tourist services still need to be courted, looked after and tenderly serviced. Moreover, the entire industry is depending on people, as tourism customers are the initial resource for business growth and company development. Managing their primary and secondary needs and desires requires specific combination of technological innovation, interpersonal skills and great knowledge of human nature.

The essential elements of a customer management, according to Joe Galvin (2018) from the MHI Research Institute, which can guarantee successful company development are:

$>$ managing relationships;

$>$ creating opportunities;

$>$ managing opportunities.

The sales culture of every professional requires understanding of what it means to manage customers and prospect relationships in order to provide a framework, giving account on cost of sales, market position, and complexity of service and product solutions. Prospecting may be a hard work and relies on the right marketing channels, many companies encourage their employees to be active in social channels, but some can do more harm than positive effect. That is why customer management hints to start managing opportunities, to invest time and resources in studying customer's decision dynamic - buying influences, issues and competitive positioning and to start forming basis for the right interaction. A good customer management strategy provides guidance and insights and on e-business initiatives working closely with the CRM, which allows the client to get the full benefit of web solutions with reduced operating costs, considering customers' presence as the leading factor to maintain the system working, to provide better support services and build long term customer loyalty.

In the digital age both organisations and customers have better choice options, versatile information sources, which assumes that provided services should be more valuable and relevant. Travel agencies start to engage in better customer segmentation based on established specific customer needs. Despite the many technological advances, many travellers still find the idea of traveling daunting and the Internet to be intimidating and are willing to pay a premium for human interaction (Rensburg, 2014).

\section{Dealing with travel agency customers and e-business}

Nowadays travel customer is better informed and has more travelling options, they have more travel experience and assessment on trip arrangements. Many travel professionals define them as "professional travellers", who have prepared well in advance for the visit at the travel office. They possess certain travel ideas and area of travelling expertise, and feel comfortable to exchange their experience and knowledge in order to obtain better travel options. In addition, the Internet and social media technologies have become entrenched in this industry and proved themselves to be the perfect tool serving clients (Rensburg, 2014), as customers are constantly using and browsing, and "digging out" the perfect available offers, the web is ready to provide. They are actually living in the digital world. Nowadays customers have in general positive acceptance for the AI tools, VR and $\mathrm{AR}$ and all the electronic assistants the ICT world is ready to provide. At times they accept them as necessity, fashion trend, travel companion, life-saver or just for the fun. The travel and tourism industry, being an adaptive and progressive one, has apprehended the idea to blend in the fashion and technological acquisitions, to get more flexibility and provide the service their customer is searching for.

Digital technology is pretty much familiar to the travel and tourism industry and especially the travel agencies. Since the 1960s, travel agencies used the Global Distribution Systems (GDS), such as Sabre (founded 1960), Amadeus (founded 1987), Galileo (founded 1988), Abacas (founded 1988) and Worldspan (founded 1993). They gave access to real-time reservation and booking 
information (Kracht, Wang, 2014). However, knowledge of the local destination, the particular communication with the native population, a significant element in the process of service provision, assists tour operators in defining the exact specifics suiting best the targeted group of customers. For professionals doing the business for more than twenty years, knowing your partner, destination and facilities at first hand is mandatory in order to prepare the best package to tourism customers. There are various typologies of tourists proposed by different authors - Murphy in 1985, Smith in 1995, but one of the most distinguishable maybe is Cohen's since 1979(Pearce, 2011), still applicable in today's world (fig.1.):
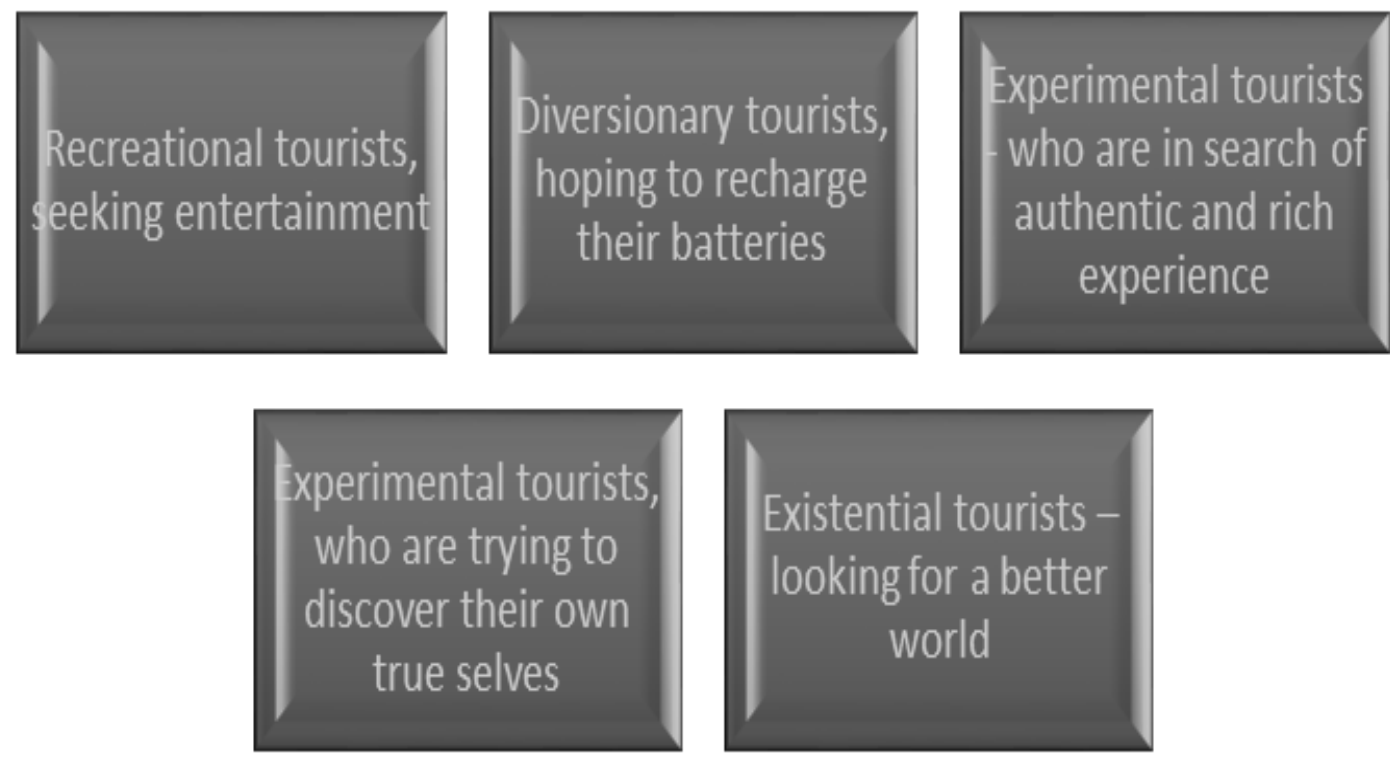

Model 1: Typology of tourists (Adapted from Cohen)

The model above is relevant and applicable even nowadays. The emerging of social media sharing, travel blogging the abundance of e-offers available just bring nuances, while attempting to discover and even portrait the profile of the travel and tourism customer. There are ones, asking for travel brochures, others are browsing numerous internet sites and blogs, others rely on the story narrated by the travel agent, but what brings them in common is - they are very sensitive to the price paid, asking for the best value in turn. Experienced travel agents are in a position to customize travel opportunities, suiting best the individual customer needs and expectations. They are at the same time sensitive to the product offered, its amenities and weak points and the certain customer being serviced. They need to perform as psychologist, identifying specific human features and behaviour models, at the same time - as professional wholesaler who is seeking for the best deal and profit to the company.

Managing nowadays tourist is a sophisticated matter. Hotel chains, restaurants, entertainment parks, airline companies, traditional tour operator and travel agencies promote competitive offers, trying to appeal to greater number of potential and real customers. Various electronic channels are at customers' disposal in order to provide more and more information, comments and suggestions. Social media has extremely great influence on its users and affects human behaviour, interests and imagination, creates inclinations on specific electronic purchases and stimulates e-business environment. But managing this kind of business still relies on the human presence in regard to the personal psychological profile of the customer and the characteristics identifying human nature. As no machine can actually provide the warm human welcoming and the personal touch, the host of the travel company is able to offer and ensure.

Moreover, in the recent years travel agency professionals are quite sensitive to developing 
sustainable and ecological tourism, as they perceive there is a vital interest. By no means, their initiative is being conducted by the wave of sustainable tourism approaches, customer interests and respect for the nature on both sides. The approach of balancing economic development, ensuring sustainment of attractions, overviewing specific psychological features of the tourists enables public agencies, governments and tourism boards to start working together. It is important for a city or country not to become too dependent on tourism, however business and governments feel necessity to make investments in infrastructure and promotion as though the percentage of unemployment is a fluctuating variable, tending to increase, and tourism industry is identifying as one continuing to grow.

Following the trends for sustainability and market newly-discoveries, travel agencies start using market signals from the electronic environment, promoting to the wide audience especially attractive spots. Differentiation according to interests, age, family status, adventure hobbies has been established and e-business comes into force in order to evaluate the approximate number of customers each branch is able to attract. Visits to certain sites, portals and blogs, number of views and comments, e-requests sent, all the digital footprints internet users leave on the web give some preliminary information to travel and tourism professionals about potential customers, their consumer profile and appeals. This helps agencies to predict and calculate tourist flows and even propose certain amenities with basic services that are more likely to tempt the profiled group of customers.

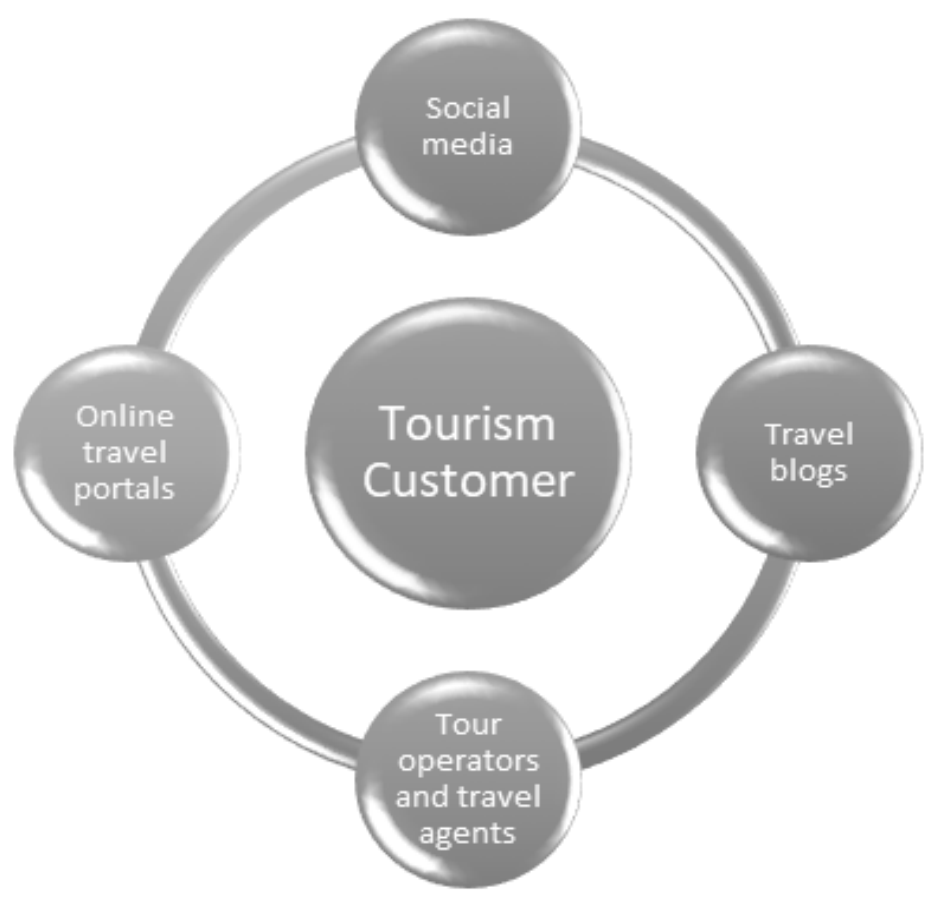

Model 2: Tourism customer interactions (Created by the author)

The model is explicitly displaying the central position of the travel and tourism customer, placed in the circle of interactions between the social media, online travel portals, the travel blogs and the classical tour operator and travel agent's figures. They represent at the same time - sources of information and competitors, fighting to attract the tourism customer's attention, bringing enjoyment, useful tips and advice. And every participant is involuntary related to the other, being both supplier, provider of information and user. And the customer is seeking for productivity, effectiveness, utility, satisfaction and happiness, in this way of speaking - the customer will always be interested in the novelty, offered new ways of experience, but requiring quality and high standards in the process of consumption. The circle represents the cycle process in seeking and 
providing customer value, driving closer customer impact, better segmentation and profitability.

No doubt, the travel and tourism industry is a typical commercial leisure industry, being dynamic part of the contemporary e-business environment. Its diversity comes right into place and competitive destinations, products, attractions flourish aiming to increase the cash flows the industry generates. Digitalization brought virtual and augmented reality and reshaped the styles of product visualization, distribution and sale it improved competition levels among travel agencies. Today, consumers are faced with a multitude of choices which complicate the buying decision process (Kracht, Wang, 2010). And the competition between the agencies is in particular due to the fashion trends nowadays tourists follow, the promotion throughout internet, television, mass-media and social media. Hence, the latest digital advancements introduced the so-called customer engagement technology (CET), which includes a wide variety of applications (social-, location-, and mobile based applications) to simplify tourism related processes (Thakran, Verna, 2013).

Electronic purchasing emerged enormously in the past decade and as "shopping is acknowledged as primary means of generating tourism revenue" and contributing local economies (Litrell et al., 2004), why not to recognize online purchasing of tourism products and services as enjoyable activity. Travel and hospitality suppliers started investing in brand websites and booking engines to offer cost effective tools for direct marketing to travellers (Thakran, Verma, 2013; Chakravarthi, Gopal, 2012; Kracht, Wang, 2010). Web portals erased the differences in the geographical reach between suppliers and customers, enabled suppliers to provide product information, visual images and allowed for the processing of direct reservations in real-time (Tsang et al., 2010). The e-commerce and online deals bring value to the travel companies as well, but in turn transform the process of customer management and actual customer servicing. In addition, famous among the travel customers innovative start-ups like Airbnb and Uber, more often become the leading factor for new competitive advantages acquiring to the stakeholders and start to blend the boundaries between e-commerce and social networks (Solnet, Golubovskaya, 2018).

An emerging group of e-shoppers used to be basically the youth market segment, but according to Euromonitor International the number is constantly increasing and what is more important the middle-aged consumers are getting more in number. The process of natural ageing of the world's population by no means results in greater group of potential e-shoppers in various stages of age. According to the UN population ageing is supposed to become one of the most significant social transformations of the current century, with serious implications for nearly all sectors of society, including labour and financial markets, the demand for goods and services and tourism of course. According to data from World Population Prospects: the 2019 Revision, by 2050, one in six people in the world will be over age 65 (16\%), up from one in 11 in $2019(9 \%)$. By 2050, one in four persons living in Europe and Northern America could be aged 65 or over. In 2018, for the first time in history, persons aged 65 or above outnumbered children under five years of age globally. The number of persons aged 80 years or over is projected to triple, from 143 million in 2019 to 426 million in 2050 (https://www.un.org/en/sections/issues-depth/.., 2019). They are already experienced travellers, being customers of the traditional travel agent and in the meantime, have already apprehended the new styles of living technology is offering. Being "oldtime" holiday makers has taught them of the principles of tourism making and way of service provision. However, they are also flexible to the balanced implementation of innovative technologies and servicing. This requires reposition of electronic strategies for the travel and tourism business in order to entice more potential and real consumers of all ages, to make satisfied customers by enabling easy-going e-purchase experience.

Customers are sensitive to the product, its price and value, the smooth process of planning and purchase in order to actually consume the whole service provided. The relation: ValueSatisfaction - Future intention is exceptionally important to be monitored by the travel agent professionals, as by studying the entire process, the agency is able to predict its customers' apprehension of the provided offers and exact supply of services. 


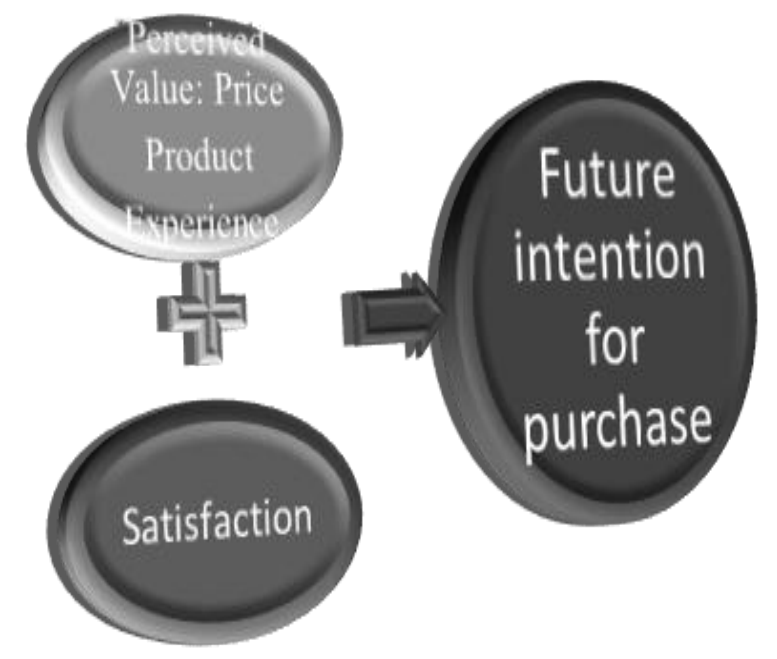

Model 3: Value- Satisfaction - Future intention Based on Research Framework (Adapted from Lloyd, Yip and Luk, 2011)

The model above aims to determine the relationship between categories as value, expectations, intentions and human aspect, all taking their place in the electronic environment, their inevitable influence affecting the whole process of tourism planning and sales. Having made a research on expectations and future intentions of the customer, assessment of the human aspect consumer's side, surveying the product value and price and its performance in an e-business environment, forms the operational strategy of the travel agency concerned. It is a crucial matter for travel agency professionals to keep attracting consumers, and as human's needs and wants keep changing, a constant view and understanding on their behaviour is mandatory to have.

\section{Research summary and conclusions}

People travel not just for the leisure activity, for many this is a form of socializing, future investments and business duties undertakings. They travel for educational or medical purposes, or just to change point of view for a certain period of time. To make the correct assessment of their priorities, behaviour and travel styles requires great knowledge of human nature and travel trends. Minding the human aspect while making a travel package, issuing a travel brochure or launching an online offer is related with the understanding of the effects and enjoyment or disappointment travel agency professional is about to bring to the customer.

The travel and tourism industry is the single one where customer and provider of services participate in the co-producing of experience (Koc, 2017), that is why professionals like Hyatt and Disney ask their employees to identify such moments as moments of truth, and even create service culture, based on the experience. Crucial moment in service, a problematic to some point, can be meeting customer's expectations. Unlike physical products, the travel and tourism ones "cannot be seen, tasted, felt, heard or smelled before it is purchased" (Kotler et al, 2017). The customer is actually relying on what have checked in a travel brochure, browsed the internet or listened to the travel agent. The risk of not meeting tourist's expectation is pretty high.

The travel agencies, in the ideal situation, do their best to promise outstanding services, by negotiating with partnering airline, hotel or transport organisations the best conditions as fair and level of quality. But as part of a value-supply chain, with many participants involved, factors from the outside influencing the whole process, service failures are often to appear. Either the attendants are not trained enough, or the employee is too tired after a too long working shift, or the customer is 
too fussy and is requiring servicing beyond real opportunities. The human aspect underlies in both type of situations and to deal with, managers need to undertake strategy of training teams how to avoid frustration, disorganization and customer complaints. It is quite a tricky thing to do, especially when the employee is lacking experience, desire or motivation in doing so.

On the other hand, a challenging matter is - dealing with the disruptive behaviour by some customers. If travel agency professional is failing to answer the exact requirements the customer is setting in front and thus can easily damage reputation, image and banish loyal and potential clients. Responding to claims and complaints, dealing with service failures and mistakes is inevitable in the travel and tourism business. And apart from the real object or product ready to be provided or replaced, even price refunded, it is important to be realized - customers need to be treated with respect. As human nature is concerned, people want to be taken seriously and to be responded to adequately and in due terms. According to Timm - "a customer complaint is an opportunity to cement a relationship and create customer loyalty". It is important for the travel agency professional to be able to respond to the customers' desires and complaints in the most appropriate way, to try to convey goodwill and professionalism (Timm, 2013), to be sensitive to their feelings and interests.

The matter discussed above is applicable today and is worth to consider when dealing with employees and co-workers as well. As travel and tourism industry is the place where people are the ones doing the service, appropriate treatment to the human labour-force is of great importance in creating healthy and fruitful working atmosphere in the travel agencies as well. Even in an ebusiness environment, human aspect is an important variable. For travel agencies who aim to develop their businesses on online platforms, thus diminishing number of employees, the need to arrange team-buildings or study courses, they still cannot afford to avoid the presence of the human labour. There will always be the need of an efficient and operational travel professional to act as the back-of-office not only dealing with problematic issues, but making real contact with the customer or intermediary. Drawbacks and loss in positions started to appear for some Bulgarian agencies orientated their business mainly in the web, they miscalculated the balancing of e-business, application of modern technologies and customer management.

On the other hand, for travel agents, benefitting from the label of the main tour operator, having been granted unlimited access to the electronic platform, there are still issues to be clarified regarding documents, tips on the destinations offered, and additional services at extra charge. On the very spot of actually consuming the travel product and service, when customers meet unexpected problems and misfortunes there is always the need of a tour operator's representative to deal with the matter, to bring solace to the customer and to avoid future claims.

\section{Conclusion}

The e-business and the digital age offer various opportunities to travel agencies to harness the benefits of information communication technologies in an affordable and simple way (Rensburg, 2014). Managing Director of GOOGLE Travel, Rob Torres, emphasized that the "the travel path to purchase is increasingly social" - either it is the help desk into force, the actual human presence, the travel package dealer, the customer relationship management system launched; all require close survey and support. E-business environment is the exact field where business initiatives take place in innovative and high-tech style, the so called Electronic Fair of trade, tourism and communications. It cannot work on its own as far as people are in question either as consumers or as participants, establishing new models of doing business.

Collecting and assessing travel customer data is the lifeblood of best offer provision and proper customer management for the travel agency. Today, in the travel and tourism sector, analysis of Big Data is commonplace, with consumer profiling, personalised services, and predictive analysis being used for marketing, advertising and management. Similar techniques could be adopted to gain real-time insights into people's wellbeing and to target aid interventions to "vulnerable" groups of unmonitored potential tourists. New sources of customer and product data, 
new technologies, and new analytical approaches, if applied responsibly, can enable more agile, efficient and evidence-based decision-making and can better measure progress on the Sustainable Development Goals (SDGs) (https://www.un.org/en/sections/issues-depth/.., 2019) in the travel and tourism business in general. Human nature, subjective people's factors are present and still a matter to be considered and assessed, as they keep having influence on the travel agencies and require further monitoring and studying by the scholars. The launch of virtual organisations, supporting ebusiness is a way to share costs, skills and access to international markets. It guarantees speed in information exchange, brings benefits to the stakeholders, and improves the product-value chain. However, it is all about social collaborations through electronic channels, which proves the statement: the human-to-human interactions will continue to influence e-business environment and be a factor to be taken into consideration when dealing with travel agency customers.

\section{References}

1. All, C., A. Engeset, I. Klepp, S. Skuland, Leisure and sustainable development in Norway: Part of the solution problem (2011), Leisure Studies, Routledge, London, UK

2. Băbăiţă, C., Ispas, A., Ghenescu, R. \& Hălălău, A., E-tourism - an important element between hotel and travel agency professional relationship (2010). Studia Universytatis Babes-Bolyai, Negotia, Lv, 4, 25-33

3. Bajpai, A. \& Lee, Ch. Consumer behaviour in e-tourism services: a case of Taiwan (2015). Tourism and Hospitality Management, 21(1), 1-17

4. Bakos, Y. The Emerging role of the electronic marketplace on the Internet, COMMUNICATIONS OF THE ACM August 1998/Vol. 41, No. 8

5. Buckly, P. Globalization and the global factory (2011), Edward Elgar, UK

6. Calvaresi, D., Al. Dubovitskaya, J. P. Calbimonte, K. Taveter, and M. Schumacher. Multi-agent systems and blockchain: Results from a systematic literature review (2018). Proceedings of the 16th International Conference on Practical Applications of Agents and Multi-Agent Systems,

7. Chakravarthi, J.S.K., V. Global, Comparison of Traditional and Online Travel Services: A Concept Note (2012). Journal of Business Strategy, 9(1): 45-58.

8. Cohen, E. A phenomenology of tourist experiences, https://doi.org/10.1177/003803857901300203, page(s): 179-201, 1979

9. Eagle, L., St. Dahl, B. Czarnecka, J. Lloyd, Marketing communications (2015), Routledge, London, UK

10. Engel, J.F., Kollat, D.T. and Blackwell, R.D. Consumer Behaviour (1968), Holt, Rinehart \&Winston, New York

11. Gelter, H. Digital Tourism - An Analysis of Digital Trends in Tourism and Customer Digital Mobile Behaviour (2017). Report, Retrieved from: resources.mynewsdesk.com/image/upload/t_attachment/ecdf34yro7o8jjvwm8ji.pdf,

12. Hitt, L. Information Technology and Firm Boundaries: Evidence from Panel Data, Information Systems Research (1999) (10:2), pp. 134-149.

13. Howard, J.; J. Sheth, The Theory of Buyer Behaviour (1969), Wiley, New York

14. Hoyer, W.D., Macinnis, D.J. \& Pieters, R. Consumer Behaviour (2012) $6^{\text {th }}$ edition

15. Inkson, Cl., L. Minnaert. Tourism management: An introduction (2018), SAGE Publications Ltd, UK Second edition

16. Kracht, J., Y. Wang, African Journal of Hospitality, Tourism and Leisure Vol. 3 (2) - (2014).

17. Koc, E., Service Failures and Recovery in Tourism and hospitality (2017), CABI

18. Kotler, Ph., J. Bowen, J. Makens, Marketing for Hospitality and Tourism (2017), Pearson, UK,

19. Kotler, Ph. Marketing Management (2014) Prentice Hall International

20. Kotler, Ph., J.T. Bowen, J. Makens, Marketing for Hospitality and tourism (2014) $6^{\text {th }}$ edition, Harlow, Pearson, UK 
21. Littrell, M., R. Paige, K. Song, Senior travellers: Tourism activities and shopping behaviour (2004), SAGE Journals, Journals of Vacation Marketing

22. Lloyd, A. L. Yip and S. Luk, "An Examination of the Differences in Retail Service Evaluation between Domestic and Tourist Shoppers in Hong Kong" (2011), Tourism Management, Vol. 32, Issue 3, 520-533

23. Nedelea, A. \& Bălan, A. E-tourism and tourism services consumer protection. Amfiteatru Economic Journal, 12(28), 492-503, 2010

24. Pan, B., E-tourism. Entry in Encyclopedia of tourism (2015), New York: Springer,

25. Pearce, Ph., Tourist Behaviour and the Contemporary World (2011), CVP, Bristol, UK

26. Rensburg, M. J., ISSN: 2223-814X, Relevance of travel agencies in the digital age (2014) African Journal of Hospitality, Tourism and Leisure Vol. 3 (2)

27. Roberts, K., The Business of Leisure, Tourism, Sport, Events and Other Leisure Industries, (2015), Red Globe Press

28. Robinson, J., Economic Development and Democracy, Annual reviews on political science, (2006), 9.092704.171256

29. Solnet, D. \& Golubovskaya, M. In Cooper, Cr., Volo, V., Gartner W.C. \& Scott, N. (Eds.). Service Management and Tourism. In The SAGE Handbook of Tourism Management (2018), SAGE Publications Ltd, UK, 269-294.

30. Timm, P. Customer Service: Career Success through customer Loyalty (2013), $6^{\text {th }}$ edition, Prentice Hall, Boston, USA

31. Thakran, K. \& Verma, R. The emergence of hybrid online distribution channels in travel, tourism and hospitality [Electronic version]. Cornell Hospitality Quarterly, 54(3), 240-247. (2013), Retrieved from: Cornell University, School of Hospitality Administration site: http://scholarship.sha.cornell.edu/articles/46/,

32. Tsang, N.K.F., Lai, M.T.H., Law, R. Measuring E-Service Quality for Online Travel Agencies (2010), Journal of Travel \& Tourism Marketing, 27(3): 306-323

33. Travel magazine, 2016

34. https://perspectivechangeconsulting.com, Accessed on 15/07/2019

35. https://www.weforum.org/, Accessed on 04/05/2019

https://www.managementstudyguide.com, Accessed on 05/05/2019

http://www2.unwto.org, Accessed on 04/05/2019

https://horwathhtl.com/publications/, Accessed on 04/05/2019

https://www.economist.com/_Accessed on 06/07/2019 